\title{
The Perceptions of Participation in a Mobile Collaborative Learning among Pre-Service Teachers
}

\author{
Shih-Hsiung Liu ${ }^{1}$ \\ ${ }^{1}$ Center for Teacher Education, National Changhua University of Education, Changhua, Taiwan \\ Correspondence: Shih-Hsiung Liu, Center for Teacher Education, National Changhua University of Education, \\ No.1 Jin-De Road, Changhua city 500, Taiwan. Tel: 886-4-723-2105. E-mail: shsiung@cc.ncue.edu.tw
}

\author{
Received: October 23, 2015 Accepted: November 18, 2015 Online Published: December 15, 2015 \\ doi:10.5539/jel.v5n1p87 URL: http://dx.doi.org/10.5539/jel.v5n1p87
}

\begin{abstract}
This study uses Facebook as a platform and arranges certain learning tasks to identify the feasibility of mobile collaborative learning for pre-service teachers. The pre-service teachers' sense of community and perceptions of collaborative learning are investigated. A total of 153 pre-service teachers volunteered to participate in an Intern Mobile Collaborative Learning Facebook Group from July 2015 to October 2015. During participating in the Facebook Group, pre-service teachers were required to achieve various tasks regarding collaborative learning. A questionnaire, consisting of three sections, frequency, sense of community, and perceptions of learning and perceptions of collaborative learning, was developed and validated. All participants were required to fill in the questionnaire at the last week of the project's schedule. This study concludes that high browsing frequency on Facebook Group could positively facilitate the sense of community and perceptions of collaborative learning among pre-service teachers; while high frequency of posting and responding to messages on Facebook Group merely promotes perceptions of collaborative learning. The conclusion identifies that assigned tasks like posting and responding to messages regarding school field-based experiences are necessary in mobile collaborative learning among pre-service teachers.
\end{abstract}

Keywords: collaborative learning, pre-service teachers, field-based experiences, Facebook group

\section{Introduction}

Collaborative learning is defined as a learning strategy in which learners are encouraged to be interdependent and be accountable for one's own and one another's learning process (Dillenbourg, 1999). Collaborative learning strategies provide learners with opportunities to receive numerous perspectives of other learners, and enhance individual critical thinking skills by comparing with, evaluating, and opposing different viewpoints (So \& Brush, 2008). Because collaborative learning strategy involves the exchange and contrast of various perspectives, the strategy specially suits the pre-service teachers who participate in the school field-based experiences in different areas. Traditionally, pre-service teachers only acquire the educational practice experiences from their practicum school. If the pre-service teachers coming from various practicum schools could mutually share individual experiences, and further discuss on the educational practices of the sharing experiences through mobile technological device, they would be able to learn more educational knowledge by reflecting their own and others' experiences.

In many countries around the world, smartphone with mobile internet has been prevalent. Notably, social media programs, such as Facebook, Line, have been equipped in the smartphone. Each pre-service teacher could exchange the information with his/her online friends anytime and anywhere. As Ke and Hsu (2015) mentioned, pre-service teachers can engage in active knowledge construction through mobile-supported collaborative learning environment.

However, pre-service teachers may have insufficient understanding of the basic principles of collaborative learning and empirical perspectives to support this practice (Gillies, Ashman, \& Terwel, 2008). Ruys, Keer, and Aelterman (2011) evidenced that pre-service teachers can perform well in collaborative learning when being trained in collaborative learning skills. On the basis of a lack of experiences in mobile collaborative learning for pre-service teachers, this study uses Facebook as a platform and arranges certain learning tasks to investigate the perceptions of collaborative learning. 


\section{Literature Review}

\subsection{Collaborative Learning for Pre-Service Teachers within Field-Based Experience}

Participating in school field-based experiences is a vital part of teacher education program. The field-based practicum should establish adequate conditions to make pre-service teachers thoughtful and to equip them with the ability to enhance educational practices (Zeichner, 1996). Specifically, the aim of field-based practicum should be educative: it should help pre-service teachers understand the role of teacher, foster the pre-service teachers' capacity to learn from school field-based experiences, and accomplish the central task of teaching - helping pupils to learn well (Graham, 2006).

Field-based experience also provides opportunities for pre-service teachers to internalize the theories learned in the campus courses into their own knowledge by practicing the theories in classroom teaching under the guidance and support of their school mentors (Cheng, 2013). The field experience is a platform to bridge the theory and practice gap in initial teacher education (Coffey, 2010; Darling-Hammond, 2006). However, pre-service teachers often feel conflicted in accepting the advice from their mentors and the university supervisors. The mentor teachers often view the university supervisor as an instructor who does not really understand the teaching practices in the K-12 classroom. The aforementioned conflicts will result in a lack of clear guidance during reflecting on educational practices for pre-service teachers.

During the half-year education practicum, each pre-service teacher could obtain a limited experience. Moreover, pre-service teacher learning is a complex process that has been conceptualized through socio-cultural and cognitive theories of learning (Darling-Hammond \& Bransford, 2005). If the pre-service teachers could share educational practices happened in individual practicum schools, they would obtain more information about school practices. Moreover, if the pre-service teachers can discuss the above school practices through an external community rather than a community inside the interior of the school, they would have more sufficient understanding on school practices.

The concepts of collaborative learning for pedagogy include self-regulated learning theory and socially shared origin of cognition (Järvelä, Näykki, Laru, \& Luokkanen, 2007). Thus, the awareness of collaboration consists of perception of learning and perception of collaborative learning. Perception of learning is about individual understanding of the process of learning and involves an individual evaluation of the educational process (Lonka, Heikilla, Lindblom-Ylanne, \& Maury, 1997). The perception of collaborative learning is related to perceptions of social presence with other members in a learning group. Ruys, van Keer, and Aelterman (2011) explored the development of pre-service teachers' skills in implementing collaborative learning and indicated that pre-service teachers perform well in collaborative learning activities, which has positive relationship with their teaching efficacy. Liu, Tsai, and Huang (2015) evidenced that pre-service teachers learned more about the instructional methods through interactions with peer interns, in addition to discussion with mentors in a school-based mentoring team. Thus, collaborative learning benefits pre-service teachers on the acquirement of knowledge of educational practices.

\subsection{Use of Social Media on Collaborative Learning for Pre-Service Teachers}

As technological tools with Internet have been gaining acceptance of teachers, they become a part of educational activities in order to support teaching and learning process, especially in the field of creating and sustaining collaborative learning strategies (Duffy \& Bruns, 2006). Studies identified that the integration of social media with mobile devices supports collaborative learning by enhancing learning performance in both individual knowledge development and group knowledge sharing. For example, Yang (2009) investigated the use of blogs as a reflective platform in the training processes and found that participants actively discussed their opinions. Participants also stated that blogs provide a useful platform for communicating with each other. Wang, Woo, Quek, Yang, and Liu (2011) denoted that Facebook could offer features similar to course management system for putting up announcements, sharing resources and conducting discussions.

Haipinge (2013) used Facebook via mobile phone to connect pre-service teachers with practicing teachers in the field. In addition to Facebook interface is designed to promote interactions, Facebook has a feature, the news feeds, showing the most recent posts and activities within the Facebook Group. In a study by Deng and Tavares (2013), the pre-service teachers considered Facebook as a good platform for them to keep instant contact rather than storing and sharing files. The Facebook Group provided the pre-service teachers with informational, social as well as intellectual support in a timely fashion during their teaching practice.

Because online setting is different from conventional classroom settings, creating a great sense of community is essential for pre-service teachers who participate in school field-based experiences from various areas. The sense 
of community is considered as a feeling of belonging and a shared faith through participants' commitments to work together (McMillan \& Chavis, 1986). To establish a sense of community, social media should be used to foster interpersonal communication rather than leading users just to complete the task for achievement grade (Cameron, Morgan, Williams, \& Kostelecky, 2009). Janssen, Erkens, Kirschner, and Kanselaar (2009) indicated that strong familiarity among members leads to critical and exploratory group perceptions, and positive perceptions of online communication and collaboration. Deng and Tavares (2012) explored that pre-service teachers' perceptions of, and participation in, online communities and suggested that pre-service teachers had positive perceptions of the community website which was regarded as a useful platform for exchanging teaching ideas, sharing resources, gaining support, and maintaining communication with their peers. The frequency of browsing community website was also correlated with the sense of community. Top (2012) indicated that the pre-service teachers had moderate feelings related to sense of community which incorporated social media and positive feelings about the collaborative learning and perceived learning.

Seo (2014) explored how teachers at different levels of participation learnt in an online community and showed that teachers usually began as observers who read online postings and used online teaching resources, then moved to collaborators, posting their comments on teaching resources and discussing their problems with other teachers. After that, they may become contributors, sharing their teaching resources with other teachers and providing advices, and assist other teachers. Yet, not all teachers moved toward full participation in the online community. The majority of teachers remained as observers and their lack of participation in the negotiation of meaning constrained teacher learning. That is, pre-service teachers with different frequency of posting and responding to messages in a social media may have different perceptions of various learning.

\subsection{Focus of This Study}

Studies that focus on the use of social media in pre-service teacher education revealed four types of results, enhancing interaction and collaboration, facilitating critical thinking and reflection, increasing active participation to activities, and increasing motivation and confidence to participate in online community in pre-service teacher education (Deng \& Yuen, 2011; Glenn, Wake, \& Modla, 2012). Thus, during mobile collaborative learning among pre-service teachers, certain tasks to facilitate their collaboration may need to be conducted. Moreover, in order to identify the feasibility of mobile collaborative learning for pre-service teachers, the sense of community and perceptions of collaborative learning among pre-service teachers merit further investigation. This study uses Facebook as a platform and arranges certain learning tasks to enhance the interaction among the pre-service teachers. During the project, the pre-service teachers' sense of community and perceptions on collaborative learning are investigated.

\section{Methodology}

\subsection{Research Design}

This study builds a Facebook Group, named as "Internship Community of Mobile Collaborative Learning" (ICMCL), to identify the feasibility of mobile collaborative learning for pre-service teachers. To achieve effective interactions among Facebook group members, four tasks were designed as follows.

First, all participating pre-service teachers need to provide the information about their practicum schools and self-expectation about field-based experiences. Second, to increase active participation in Facebook Group, two tasks regarding educational practices in school practicum are assigned in each month. The tasks involve the practices of school administration, classroom management, lesson preparation, and teaching and reflection. All members are required to post at least an opinion in the below area of each task item. Third, all members need to respond at least once to any posting from others after being encouraged to practice critical thinking and reflection. Fourth, all members are encouraged to raise their problems that happen in their practicum schools at any time. Additionally, to increase motivation and self-confidence to use Facebook Group community, the researcher often reinforced the members who disclosed problems of practicum and responders to the problems.

All participants were encouraged to use mobile technology device to interact with other members on Facebook Group. During the project, nine task items were assigned. All participants achieved the posts to the tasks. Except for the posts and responses for the tasks, a total of 148 problems were raised and obtained 321 responses to the problems.

\subsection{Research Participants}

A total of 153 pre-service teachers were willing to participate in the ICMCL project from July 2015 to October 2015. The pre-service teachers graduated from a teacher education university in the middle of Taiwan; however, they enrolled in the filed-based experience of schools distributing over the country. The participants, consisting 
of 41 male (26.8\%) and 112 female (73.2\%), enrolled in practicum at senior high school (40, 26.1\%), at vocational high school $(22,14.1 \%)$, at junior high school $(89,58.2 \%)$ and at special education school $(2,1.3 \%)$.

All participants have mobile technology device, such as smartphone, tablet. The majority of the participants expressed that mobile technology device is the main tool to browse, and respond to, the Facebook Group due to convenience. All participants volunteered to sign an agreement, participating in this ICMCL project after being fully informed about the research process, potential harm, and important rights, such as the right to cease participation or withdraw from the research at any time without suffering discrimination or harm.

\subsection{Instrument}

This study developed a questionnaire to collect the data about frequency (browsing, posting and responding), sense of community, and self-perceived collaborative learning. Thus, the questionnaire consisted of the three sections. The original items were developed in Chinese, and latter, were translated into English for submission.

The first section, baseline data, contains gender, the type of practicum school with field-based experience, frequency of browsing Facebook Group, and frequency of posting and responding to messages. Each type of the frequency consists of four levels: less than 3 times per month, once per week, 2 or 3 times per week, and once or more per day.

The second section, sense of community, includes three categories: 1). self-perceived online media and tools, 2). perceived media-based human interactions, and 3). learner satisfaction. Each category has three items that were developed by referring to Lu, Yang, and Yu (2013). An example item is "the ICMCL helps me reflect on some perspectives on my practicum".

The third section is self-perceived collaborative learning, which contains two parts: the perceptions of mobile learning and the perceptions of collaborative learning. Each part has five items that were developed by referring to Halic, Lee, Paulus, and Spence (2010). An example item is "I have thought of what information I could provide with to expand practicum experiences of others".

All participants were required to fill in the questionnaire at the last week of the project's schedule. Responses to each item in the second and the third section were provided on a 5-point Likert scale ranging from 1 (strongly disagree) to 5 (strongly agree). All items were repeatedly revised by three professors with relevant expertise. A factor analysis was conducted. Cronbach's alpha was initially calculated to assess the internal consistency and reliability of the sections.

The calculated results of the items in the second section reveal that the Kaiser-Meyer-Oklin (KMO) value was 0.909 and Bartlett's Test of Sphericity reached statistical significance $(\mathrm{p}<.001)$, supporting the factorability of the correlation matrix. Only one factor was emerged with eigenvalues $>1$ and accounted for $61.45 \%$ of variance, with responses with loadings of $0.749-0.826$ on the factor. The Cronbach's alpha value for the section was 0.919 .

In the third section, the calculated results show that the initial KMO value was 0.835 and Bartlett value reached statistical significance. Two items were deleted due to the responses with loadings of 0.046 and 0.258 . Afterwards, the factor analysis was conducted again. The final KMO was 0.858 and Bartlett value reached statistical significance. Only one factor was emerged with eigenvalues $>1$ and accounted for $57.93 \%$ of variance, with responses with loadings of $0.607-0.859$ on the factor. The Cronbach's alpha value for the section was 0.888 .

\subsection{Data Analysis}

As mentioned, two types of the frequency were contained in the first section of the instrument. However, two-way analysis of variance (ANOVA) cannot be adopted due to inadequate subjects. A suggested number is 20 times of all independent variable combination. That is, a total of 320 subjects is a suggested number for using two-way ANOVA, while this study only contains 153 subjects in this study.

Data were analyzed using one-way ANOVA to identify differences in various perceptions of participations between the frequencies of browsing, and posting and responding to messages on Facebook Group. By identifying whether the frequencies of browsing, and posting and responding to messages influence the perceptions of participations in the Facebook Group, this study could evaluate the feasibility of mobile collaborative learning.

\section{Results}

The analytical results of this study reveal that the difference exists in the sense of community between various frequencies of browsing the Facebook Group $(F=13.426, p<.01)$. Of which various frequencies, the more frequency the pre-service teachers performed in browsing the Facebook Group, the more sense of community 
they had. Similar to the effect of the browsing frequency on the sense of community, the more frequency the pre-service teachers performed in browsing the Facebook Group, the more perceptions of learning $(F=7.112$, $p<.01)$ as well as perceptions of collaborative learning $(F=4.220, p<.01)$ they had.

The above finding indicates that the browsing frequency on the Facebook Group is an important element of facilitating the perception of participation in collaborative learning for pre-service teachers.

Moreover, another analytical results reveal that no difference exists in the sense of community $(F=2.052, p>.01)$ as well as perceptions of learning $(F=1.130, p>.01)$ between various frequencies of posting and responding to messages on Facebook Group. However, the pre-service teachers with higher frequency of posting and responding to messages had higher perceptions of collaborative learning. That is, the pre-service teachers who often posted and responded to messages on Facebook Group could experience the advantages of collaborative works.

Table 1. Summary table of one-way ANOVA on considered factors by frequency of browsing the Facebook Group

\begin{tabular}{|c|c|c|c|c|c|c|}
\hline Variables & $\begin{array}{l}\text { Frequency of browsing the Facebook } \\
\text { Group }\end{array}$ & $N$ & $M$ & $S D$ & $F$ & Scheffe \\
\hline \multirow{4}{*}{$\begin{array}{l}\text { Sense of } \\
\text { community }\end{array}$} & Less than 3 times per month (A) & 16 & 3.18 & 0.83 & \multirow{4}{*}{$13.426^{*}$} & $\mathrm{D}>\mathrm{A}$ \\
\hline & Once per week (B) & 28 & 3.72 & 0.60 & & $\mathrm{D}>\mathrm{B}$ \\
\hline & 2 or 3 times per week (C) & 62 & 3.88 & 0.45 & & $\mathrm{C}>\mathrm{A}$ \\
\hline & Once or more per day (D) & 47 & 4.18 & 0.56 & & $\mathrm{~B}>\mathrm{A}$ \\
\hline \multirow{4}{*}{$\begin{array}{l}\text { Perception of } \\
\text { learning }\end{array}$} & Less than 3 times per month (A) & 16 & 3.44 & 0.88 & \multirow{4}{*}{$7.112^{*}$} & $\mathrm{D}>\mathrm{A}$ \\
\hline & Once per week (B) & 28 & 3.92 & 0.41 & & $\mathrm{C}>\mathrm{A}$ \\
\hline & 2 or 3 times per week $(\mathrm{C})$ & 62 & 3.90 & 0.45 & & $\mathrm{~B}>\mathrm{A}$ \\
\hline & Once or more per day (D) & 47 & 4.09 & 0.40 & & \\
\hline \multirow{4}{*}{$\begin{array}{l}\text { Perception of } \\
\text { collaborative } \\
\text { learning }\end{array}$} & Less than 3 times per month (A) & 16 & 3.39 & 1.01 & \multirow{4}{*}{$4.220^{*}$} & $\mathrm{D}>\mathrm{A}$ \\
\hline & Once per week (B) & 28 & 3.66 & 0.61 & & \\
\hline & 2 or 3 times per week (C) & 62 & 3.78 & 0.54 & & \\
\hline & Once or more per day (D) & 47 & 3.97 & 0.48 & & \\
\hline
\end{tabular}

${ }^{*} p<.01$

Table 2. Summary table of one-way ANOVA on considered factors by frequency of posting and responding to messages

\begin{tabular}{lllllll}
\hline Variables & $\begin{array}{l}\text { Frequency of posting and responding to } \\
\text { messages }\end{array}$ & $N$ & $M$ & $S D$ & $F$ & Scheffe \\
\hline \multirow{3}{*}{ Sense of } & Less than 3 times per month (A) & 71 & 3.87 & 0.56 & & \\
community & Once per week (B) & 31 & 3.85 & 0.51 & 2.052 & n.s. \\
& 2 or 3 times per week (C) & 38 & 3.95 & 0.43 & & \\
& Once or more per day (D) & 13 & 4.23 & 0.45 & & \\
\multirow{4}{*}{ Perception of } & Less than 3 times per month (A) & 71 & 3.75 & 0.64 & & \\
learning & Once per week (B) & 31 & 3.80 & 0.67 & & n.s. \\
& 2 or 3 times per week (C) & 38 & 3.71 & 0.53 & & \\
& Once or more per day (D) & 13 & 4.06 & 0.56 & & \\
\hline
\end{tabular}




\begin{tabular}{lllllll}
\hline & Less than 3 times per month (A) & 71 & 3.67 & 0.65 & & D $>A$ \\
Perception of & Once per week (B) & 31 & 3.83 & 0.59 & $8.276^{*}$ & D $>$ B \\
collaborative & 2 or 3 times per week (C) & 38 & 4.10 & 0.47 & & C $>A$ \\
learning & Once or more per day (D) & 13 & 4.38 & 0.47 & & \\
& & & & &
\end{tabular}

\section{Discussion}

This present study shows that the browsing frequency on the Facebook Group is an important element of facilitating the perception of participation in collaborative learning for pre-service teachers. According to Deng and Tavares (2012), pre-service teachers had positive perceptions of the online website when they considered the website as a useful platform for exchanging teaching ideas, sharing resources and gaining support. Deng and Tavares indicated that the frequency of browsing website was also correlated with the sense of community. Thus, similar to the study by Deng and Tavares, this study identified that high browsing frequency on Facebook Group could positively facilitate the sense of community and perceptions of learning as well as collaborative learning for pre-service teachers.

Another study finding shows that the pre-service teachers who often posted and responded to messages on the Facebook Group had high perceptions of collaborative learning rather than that of the sense of community and of learning. So and Brush (2008) indicated that collaborative learning strategies can provide learners with opportunities to receive numerous perspectives of other learners, and also enhance their critical thinking skills by comparing with, evaluating, and opposing different viewpoints. According to Haipinge (2013), pre-service teachers may reflect on their learning through online discussions and postings. Pre-service teachers can engage in active knowledge construction through mobile computer-supported collaborative learning environment (Ke \& Hsu, 2015). Thus, posting and responding on Facebook pages about teaching practices can facilitate pre-service teachers' reflections on their learning and enhance their perceptions of collaborative learning. Additionally, the sense of community is only a feeling that members have of belonging (McMillan \& Chavis, 1986). Perception of learning merely involves an individual evaluation of the educational process (Lonka, Heikilla, Lindblom-Ylanne, \& Maury, 1997). This is why the pre-service teachers who often posted and responded on Facebook pages had high perceptions of collaborative learning rather than that of the sense of community and of learning.

\section{Conclusion and Limitation}

This study aims to investigate the perceptions of participation in mobile collaborative learning within a Facebook group among pre-service teachers who participate in various school field-based experiences and concludes that high browsing frequency on Facebook Group could positively facilitate the sense of community and perceptions of learning as well as collaborative learning for pre-service teachers; while high frequency of posting and responding to messages on Facebook Group experienced the advantages of collaborative works rather than that of the sense of community and of learning. This study highlights that sharing experiences and online discussion regarding practicum are the important elements of mobile collaborative learning for pre-service teachers. The conclusion also identifies that the posts and responses as assigned tasks involving the elements of school field-based experiences are necessary in mobile collaborative learning among pre-service teachers.

This study can calculate the frequency of posting and responding on Facebook pages but cannot obtain real frequency of browsing the Group. Instead, this study relied on self-reports of pre-service teachers regarding browsing the Group. Thus, this study has one limitation: the frequency of browsing the Facebook Group may differ because the participants may not accurately recall all browsing records during filling in the instruments of the study.

\section{References}

Cameron, B. A., Morgan, K., Williams, K. C., \& Kostelecky, K. L. (2009). Group projects: Students perceptions of the relationship between social tasks and a sense of community in online group work. The American Journal of Distance Education, 23(1), 20-33. http://dx.doi.org/10.1080/08923640802664466

Cheng, E. C. K. (2013). Enhancing the quality of pre-service teachers' learning in teaching practicum. Education Sciences, 1, 6-16.

Coffey, H. (2010). "They taught me": The benefits of early community-based field experiences in teacher education. Teaching and Teacher Education, 26(2), 335-342. http://dx.doi.org/10.1016/j.tate.2009.09.014 
Darling-Hammond, L., \& Bransford, J. (Eds.). (2005). Preparing teachers for a changing world: What teachers should learn and be able to do. San Francisco: Jossey-Bass.

Darling-Hammond, L. (2006). Powerful teacher education: Lesson for exemplary programs. San Francisco: Jossey-Bass.

Deng, L., \& Tavares, N. (2012). Exploring pre-service teachers' perceptions of and participation in online communities (pp. 787-791). Paper presented at the Proceedings of the 20th International Conference on Computers in Education.

Deng, L., \& Tavares, N. (2013). From Moodle to Facebook: Exploring students' motivation and experiences in $\begin{array}{lllll}\text { online communities. } \quad \text { Computers } \& \text { Education, } & \text { 68, }\end{array}$ http://dx.doi.org/10.1016/j.compedu.2013.04.028

Deng, L., \& Yuen, A. H. K. (2011). Towards a framework for educational affordances of blogs. Computers \& Education, 56(2), 441-451. http://dx.doi.org/10.1016/j.compedu.2010.09.005

Dillenbourg, P. (1999). What do you mean by collaborative learning? In P. Dillenbourg (Ed.), Collaborative learning: Cognitive and computational approaches (pp. 1-19). Oxford: Elsevier.

Duffy, P. D., \& Bruns, A. (2006). The use of blogs, wikis and RSS in education: A conversation of possibilities. Paper presented at the Online Learning and Teaching Conference, Brisbane.

Gillies, R., Ashman, A., \& Terwel, J. (2008). The teachers' role in implementing cooperative learning in the classroom. New York: Springer. http://dx.doi.org/10.1007/978-0-387-70892-8

Glenn Wake, D., \& Modla, V. B. (2012). Using wikis with teacher candidates: Promoting collaborative practice and contextual analysis. Journal of Research on Technology in Education, 44(3), 243-265. http://dx.doi.org/10.1080/15391523.2012.10782589

Graham, B. (2006). Conditions for successful field experiences: Perceptions of cooperating teachers. Teaching and Teacher Education, 22, 1118-1129. http://dx.doi.org/10.1016/j.tate.2006.07.007

Haipinge, K. (2013). Using Facebook Mobile as a tool to create a virtual learning community for pre-service teachers. In S. P. Ferris, \& H. A. Wilder (Eds.), Plugged-in professor: Tips and techniques for teaching with social media (pp. 289-299). Chandos Publishing. http://dx.doi.org/10.1016/b978-1-84334-694-4.50023-5

Halic, O., Lee, D., Paulus, T., \& Spence, M. (2010). To blog or not to blog: Student perceptions of blog effectiveness for learning in a college-level course. Internet and Higher Education, 13(4), 206-213. http://dx.doi.org/10.1016/j.iheduc.2010.04.001

Janssen, J., Erkens, G., Kirschner, P. A., \& Kanselaar, G. (2009). Influence of group member familiarity on online collaborative learning. Computers in Human Behavior, 25(1), 161-170. http://dx.doi.org/10.1016/j.chb.2008.08.010

Järvelä, S., Näykki, P., Laru, J., \& Luokkanen., T. (2007). Structuring and regulating collaborative learning in higher education with wireless networks and mobile tools. Educational Technology \& Society, 10(4), 71-79.

Ke, F.-F., \& Hsu, Y.-C. (2015). Mobile augmented-reality artifact creation as a component of mobile computer-supported collaborative learning. The Internet and Higher Education, 26, 33-41. http://dx.doi.org/10.1016/j.iheduc.2015.04.003

Liu, S.-H., Tsai, H.-C., \& Huang, Y.-T. (2015). Collaborative professional development of mentor teachers and pre-service teachers in technology integration. Educational Technology \& Society, 18(3), 161-172.

Lonka, K., Heikilla, A., Lindblom-Ylanne, S., \& Maury, S. (1997). Are epistemologies related to study activities in an innovative course? Paper presented at the 7th European Conference for Research on Learning and Instruction, Athens, Greece.

McMillan, D. W., \& Chavis, D. M. (1986). Sense of community: A definition and theory. Journal of Community Psychology, 14(1), 6-23. http://dx.doi.org/10.1002/1520-6629

Ruys, I., Van Keer, H., \& Aelterman, A. (2011). Student teachers' skills in the implementation of collaborative learning: A multilevel approach. Teaching and Teacher Education, 27, 1090-1100. http://dx.doi.org/10.1016/j.tate.2011.05.005

So, H. J., \& Brush, T. A. (2008). Student perceptions of collaborative learning, social presence and satisfaction in a blended learning environment: Relationships and critical factors. Computers \& Education, 51(1), 318-336. http://dx.doi.org/10.1016/j.compedu.2007.05.009 
Top, E. (2012). Blogging as a social medium in undergraduate courses: Sense of community best predictor of perceived learning. The Internet and Higher Education, 15, 24-28. http://dx.doi.org/10.1016/j.iheduc.2011.02.001

Wang, Q., Woo, H. L., Quek, C. L., Yang, Y., \& Liu, M. (2011). Using the Facebook group as a learning management system: An exploratory study. British Journal of Educational Technology, 43(2), 428-438.

Yang, S. H. (2009). Using blogs to enhance critical reflection and community of practice. Educational Technology \& Society, 12(2), 11-21.

Zeichner, K. (1996). Designing educative practicum experiences for prospective teachers. In Zeichner, Melnick, \& Gomez (Eds.), Currents of reform in pre-service teacher education. New York: Teachers College Press.

\section{Copyrights}

Copyright for this article is retained by the author(s), with first publication rights granted to the journal.

This is an open-access article distributed under the terms and conditions of the Creative Commons Attribution license (http://creativecommons.org/licenses/by/3.0/). 